\title{
Chapter 18 \\ Moisture Stable Soot Coated \\ Methylammonium Lead Iodide \\ Perovskite Photoelectrodes for Hydrogen \\ Production in Water
}

\section{Udit Tiwari and Sahab Dass}

\begin{abstract}
Metal halide perovskites have triggered a quantum leap in the photovoltaic technology marked by a humongous improvement in the device performance in a matter of just a few years. Despite their promising optoelectronic properties, their use in the photovoltaic sector remains restricted due to their inherent instability towards moisture. Here, we report a simple, cost-effective and highly efficient protection strategy that enables their use as photoelectrodes for photoelectrochemical hydrogen production while being immersed in water. A uniform coating of candle soot and silica is developed as an efficient hydrophobic coating that protects the perovskite from water while allowing the photogenerated electrons to reach the counter electrode. We achieve remarkable stability with photocurrent density above $1.5 \mathrm{~mA} \mathrm{~cm}{ }^{-2}$ at $1 \mathrm{~V}$ versus saturated calomel electrode (SCE) for $\sim 1 \mathrm{~h}$ under constant illumination. These results indicate an efficient route for the development of stable perovskite photoelectrodes for solar water splitting.
\end{abstract}

Keywords Photoelectrochemical water splitting - Halide perovskites - Hydrogen • $\mathrm{TiO}_{2} \cdot \mathrm{CH}_{3} \mathrm{NH}_{3} \mathrm{PbI}_{3}$

\subsection{Introduction}

The world has entered into an era where climate change has become an unfortunate reality [1]. Any further increase in the $\mathrm{CO}_{2}$ levels might push the Earth's climate over a tipping point from which recovery would become impossible [2]. The unprecedented pace at which global warming is damaging the earth is evident from the warming of the oceans and the accelerated melting of the polar ice caps all of which point to the increasing level of the greenhouse gases [3]. There is thus an urgent need for the world

U. Tiwari $(\otimes)$

School of Physical Sciences and Computing, University of Central Lancashire,

Preston PR1 2HE, UK

e-mail: UTiwari1@uclan.ac.uk

S. Dass

Department of Chemistry, Dayalbagh Educational Institute, Agra 282005, India

(C) The Author(s) 2021

I. Mporas et al. (eds.), Energy and Sustainable Futures, Springer Proceedings in Energy, https://doi.org/10.1007/978-3-030-63916-7_18 
to shift from the conventional carbon-based fuels to a renewable energy source to tackle global warming while also fulfilling the global energy demands. In this regard, hydrogen can be seen as the best alternative energy source as it is absolutely clean $(\mathrm{C} / \mathrm{H}$ ratio is 0$)$, freely available (most abundant element), has a very high energy per unit mass ( $1 \mathrm{~kg}$ of hydrogen provides the same power as $3.78 \mathrm{~L}$ of gasoline) and has a high energy storage capacity per mole [4]. Currently, hydrogen production mainly relies on methane steam reforming and electrolysis both of which cannot be considered environment-friendly and thus defeats the purpose of producing hydrogen [5]. Amongst renewable methods of hydrogen production, the photoelectrochemical splitting of water is considered to be the most promising method which uses semiconductors submerged in aqueous electrolyte as photo-absorbers for sunlight driven splitting of water [6]. However, the development of inexpensive and moisture stable visible light-absorbing materials is still a challenging task [7]. Hybrid Organometal halide perovskites offer great promise as photoelectrode materials thanks to their low cost, easy processability, high efficiency [8], tunable band-gap [9], ambipolar charge transport [10], long carrier lifetimes [11], and long charge diffusion lengths [12]. The immense potential of these materials is evident from the rapid improvement in their power conversion efficiencies from over 3.8\% in 2009 to values reaching over $23 \%$ in 2018 making it the fastest growing technology in the history of photovoltaics [13]. Despite the tremendous promise shown by these materials, their wide-scale commercialisation is restricted owing to one major drawback; they are inherently unstable in water. The lattice of methylammonium lead iodide perovskite degrades even with the slightest exposure to moisture, followed by the decomposition of the material into $\mathrm{PbI}_{2}$ [14]. Several attempts have been made to improve the stability of halide perovskites towards moisture, including protective surface coatings, use of more hydrophobic alkyl ammonium salts, atomic layer deposition or through 2D/3D hybrid structures [15]. These protection strategies are not only expensive but also fail to impart long term stability to the perovskite photoelectrodes and therefore are difficult to upscale.

Here we report a simple, cost-effective and efficient protection strategy to enable the perovskite photoelectrodes to produce hydrogen while being submerged in an aqueous electrolyte. A thin layer of silica over a uniform layer of candle soot is used to effectively protect the moisture-sensitive $\mathrm{CH}_{3} \mathrm{NH}_{3} \mathrm{PbI}_{3}$ (referred to as $\mathrm{MAPbI}_{3}$ ) perovskite layer from degradation in water. The combination of carbon and silica served as an effective hydrophobic layer shielding the photoelectrodes from water. The $\mathrm{m}-\mathrm{TiO}_{2}\left|\mathrm{MAPbI}_{3}\right| \mathrm{ClSiO}$ photoanodes operate in water, exhibiting photocurrents of over $1.8 \mathrm{~mA} / \mathrm{cm}^{2}$ at an applied bias of $1 \mathrm{~V}$ in an alkaline solution ( $\left.\mathrm{pH} 13\right)$. Even more impressively, these photoelectrodes exhibit remarkable stability showing no considerable change in the current for over $1 \mathrm{~h}$ under constant illumination. 


\subsection{Experimental}

\subsubsection{Synthesis of Methylammonium Lead Iodide}

$30 \mathrm{~mL}$ Hydroiodic acid (57 wt.\% in water, Aldrich) was added dropwise to $27.86 \mathrm{~mL}$ methylamine ( $40 \%$ in methanol, Aldrich) in a $250 \mathrm{~mL}$ round-bottomed flask and was subjected to constant magnetic stirring at $0{ }^{\circ} \mathrm{C}$ for $2 \mathrm{~h}$. Crystallization was done by evaporating the solvents at $50{ }^{\circ} \mathrm{C}$ for $1 \mathrm{~h}$. The obtained powder was purified by washing three times with diethyl ether, followed by drying at $60{ }^{\circ} \mathrm{C}$ in a vacuum oven for $24 \mathrm{~h}$. The product, methylammonium iodide was saved at room temperature in a desiccator [16].

\subsubsection{Solar Cell Fabrication}

A compact layer of $\mathrm{TiO}_{2}$ as an electron transport layer (ETM) was deposited onto the FTO substrates by spin coating a solution containing $0.65 \mathrm{ml}$ of Ti (IV) isopropoxide (Sigma Aldrich, 97\%), $0.38 \mathrm{ml}$ of Acetylacetone (Sigma Aldrich, reagent grade) and $5 \mathrm{ml}$ of Ethanol at $3000 \mathrm{rpm}$ for $60 \mathrm{~s}$. The substrates were then calcined at $500{ }^{\circ} \mathrm{C}$ for 30 min to obtain the dense $\mathrm{TiO}_{2}$ layer. The perovskite precursor solution was prepared by mixing $\mathrm{CH}_{3} \mathrm{NH}_{3} \mathrm{PbI}_{3}$ and $\mathrm{PbI}_{2}$ (1:1 mol ratio) in $\gamma$-butyrolactone at $60{ }^{\circ} \mathrm{C}$ for $12 \mathrm{~h}$ with constant magnetic stirring. The resulting solution was coated onto the $\mathrm{FTO} / \mathrm{TiO}_{2}$ substrate at 2,000 rpm for $60 \mathrm{~s}$ then at 3,000 rpm for $60 \mathrm{~s}$, and dried on a hot plate at $100{ }^{\circ} \mathrm{C}$ for $2 \mathrm{~min}$ [16]. A uniform layer of soot was immediately deposited onto the $\mathrm{FTO} / \mathrm{TiO}_{2} / \mathrm{MAPbI}_{3}$ substrate with the help of a burning candle, followed by the spin-coating of a uniform layer of $\mathrm{SiO}_{2}\left(0.1 \mathrm{~g} \mathrm{SiO}_{2}\right.$ in $2 \mathrm{~mL} \gamma$ butyrolactone) over it. These $\mathrm{FTO} / \mathrm{TiO}_{2} / \mathrm{MAPbI}_{3} / \mathrm{C} / \mathrm{SiO}_{2}$ substrates (see Fig. 18.1) were developed into photoelectrodes by establishing ohmic electrical contacts using

Fig. 18.1 3D configuration of soot coated perovskite device

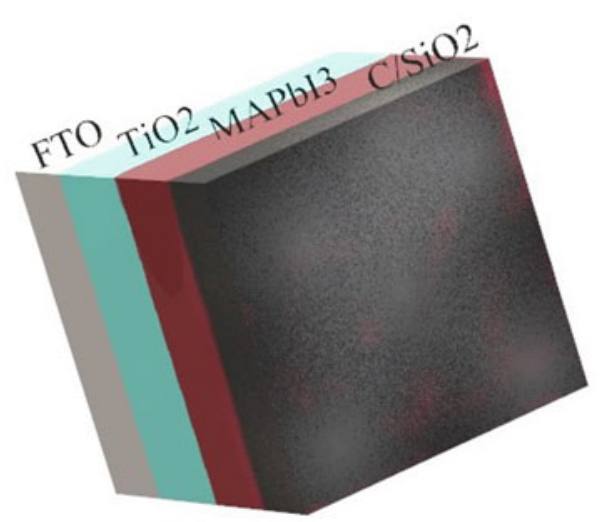


silver paste and copper wire from the uncoated area of the conductive substrates. The area of contact was then covered with non-transparent and non-conducting epoxyresin (Hysol, Singapore).

\subsection{Results and Discussion}

\subsubsection{Analysis of the Crystal Structure}

Figure 18.2 shows the XRD pattern of the soot coated perovskite thin film. The peaks at $14.08^{\circ}, 28.36^{\circ}, 31.76^{\circ}$, and $43.08^{\circ}$ correspond to the tetragonal $/ \beta$ phase of $\mathrm{MAPbI}_{3}$ oriented along the (110), (220), (310,) and (330) planes respectively (JCPDS 00-021-1276). The peaks at $25.304^{\circ}, 37.793^{\circ}$ and $48.037^{\circ}$ correspond to the (101), (004), and (200) planes respectively of the tetragonal phase of $\mathrm{TiO}_{2}$ (JCPDS $65-5714)$. The peaks at $2 \theta$ values of $15.194^{\circ}, 16.966^{\circ}$ and $26.544^{\circ}$ correspond to the (110), (003) and (300) planes respectively of carbon (JCPDS 50-0927), while those at $10.892^{\circ}$ and $40.265^{\circ}$ correspond to the (101) and (005) planes respectively of $\mathrm{SiO}_{2}$ (JCPDS 771414). All other peaks correspond to the FTO substrate. The XRD pattern reveals that both $\mathrm{MAPbI}_{3}$ and $\mathrm{TiO}_{2}$ are obtained in a highly crystalline state while also indicating the presence of carbon and $\mathrm{SiO}_{2}$. Moreover, the coating of soot over the perovskite layer does not alter its crystalline structure suggesting that carbon did not incorporate into the crystal lattice of the perovskite.

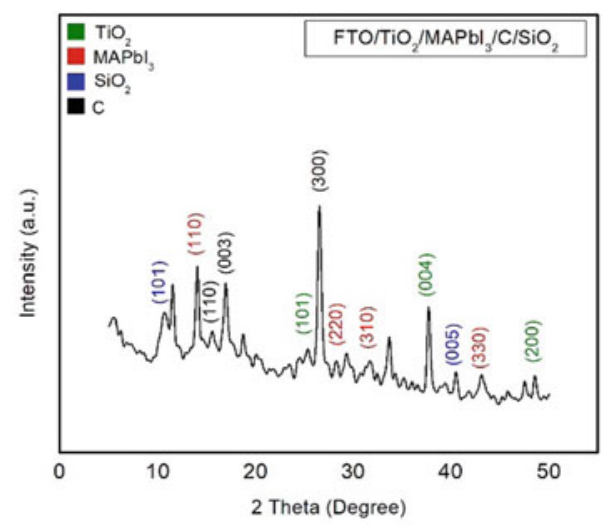

Fig. 18.2 XRD pattern of the $\mathrm{FTO} / \mathrm{TiO}_{2} / \mathrm{MAPbI}_{3} / \mathrm{C} / \mathrm{SiO}_{2}$ photoelectrode 


\subsubsection{Optical Measurements}

The optical absorbance measurements were made using a UV-Visible Spectrophotometer (Shimadzu, UV-2450, Japan) in the wavelength range of 800 to $200 \mathrm{~nm}$ using a UV quartz sample cell with a transmission range of 190-2500 $\mathrm{nm}$. The UV-Visible spectra (Fig. 18.3a) compares the absorption characteristics of the pure perovskite $\left(\mathrm{FTO} / \mathrm{MAPbI}_{3}\right)$ and the soot coated perovskite photoelectrode $\left(\mathrm{FTO} / \mathrm{TiO}_{2} / \mathrm{MAPbI}_{3} / \mathrm{C} / \mathrm{SiO}_{2}\right.$ ). The spectra show that the incorporation of $\mathrm{TiO}_{2}$ and carbon as electron transport layer (ETL) and hole transport layer (HTL) respectively results in the shifting of the absorption towards the ultraviolet region. The band-gap energies were calculated by the absorbance data using the following equation:

$$
\alpha h v=A\left(h v-E_{g}\right)^{m}
$$

where $\alpha$ is the absorption coefficient, hv is the photon energy in $\mathrm{eV}$, and $\mathrm{E}_{\mathrm{g}}$ is the band-gap energy in $\mathrm{eV}$. A is a constant related to the effective mass of the electrons and holes and $\mathrm{m}$ is equal to 0.5 for allowed direct transition and 2 for an allowed indirect transition. Plots between $(\alpha h v)^{2}$ and hv for the pristine perovskite and the soot coated perovskite are shown in Fig. 18.3b, c respectively. The linear nature of the graph suggests that the sample behaves as a direct band-gap material. The bandgap for the pristine perovskite sample comes out to be $2.05 \mathrm{eV}$ close to the reported value of $1.56 \mathrm{eV}$ [7] while for the soot coated perovskite, it comes out to be $2.49 \mathrm{eV}$. The high band gap $\mathrm{SiO}_{2}$ layer may have resulted in the overall increase in the device band gap.

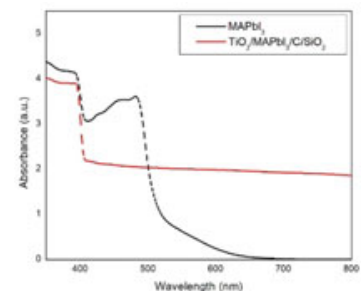

A

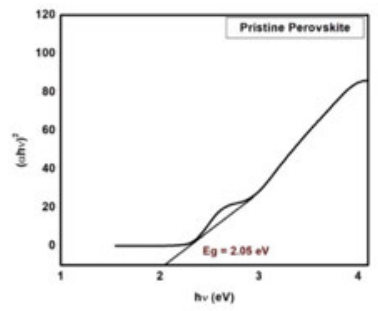

B

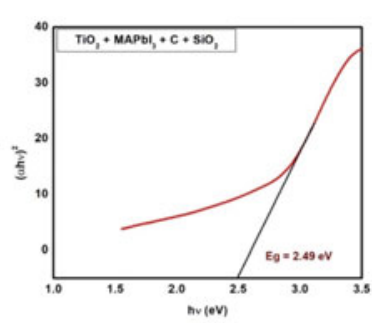

C

Fig. 18.3 a Absorption spectra of the $\mathrm{FTO} / \mathrm{MAPbI}_{3}$ and $\mathrm{FTO} / \mathrm{TiO}_{2} / \mathrm{MAPbI} / \mathrm{C}_{3} / \mathrm{SiO}_{2}$ thin films. b Tauc plot for the pristine perovskite sample $\left(\mathrm{FTO} / \mathrm{MAPbI}_{3}\right)$. c Tauc plot for the soot coated perovskite sample 
Fig. 18.4 Photocurrent density voltage characteristics of the soot coated perovskite photoelectrode in $0.1 \mathrm{M}$ $\mathrm{NaOH}$ electrolyte

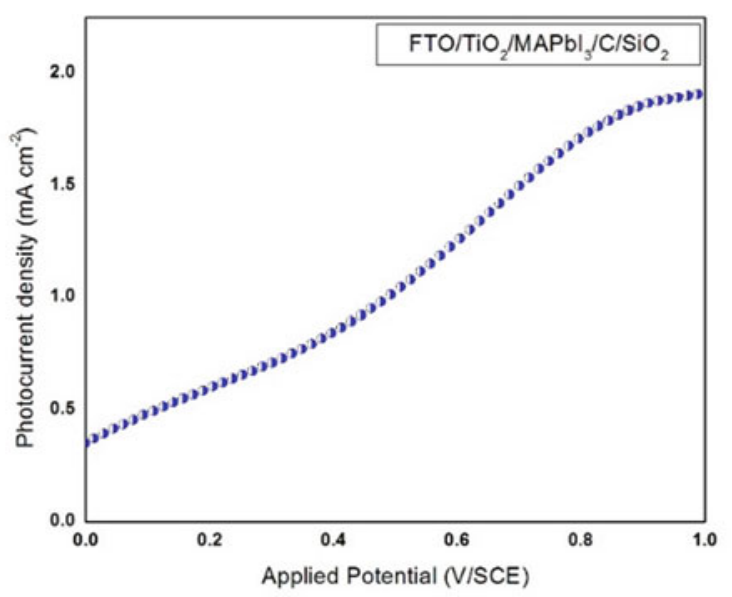

\subsubsection{Photoelectrochemical Measurements}

The photosensitivity of the prepared electrode is analysed by investigating its current versus voltage characteristics in a three-electrode quartz cell under light and dark conditions. Figure 18.4 shows the photocurrent density of the photoelectrode as a function of the electrode potential. The $\mathrm{FTO} / \mathrm{TiO}_{2} / \mathrm{MAPbI}_{3} / \mathrm{C} / \mathrm{SiO}_{2}$ combination yielded a photocurrent density of $1.8 \mathrm{~mA} \mathrm{~cm}^{-2}$ at an applied bias of $1 \mathrm{VSCE}$. The excellent photo-response of the soot coated perovskite photoelectrode suggests that the hydrophobic soot/ $\mathrm{SiO}_{2}$ coating did not interfere with the photoelectrochemical response of the perovskite. The stability of the prepared photoelectrodes is investigated by measuring the current versus time characteristics in a PEC cell. Figure 18.5 shows Chronoamperometry recorded at an applied potential of $1 \mathrm{~V}$ versus SCE in a

Fig. 18.5

Chronoamperometric analysis of the soot coated photoelectrode

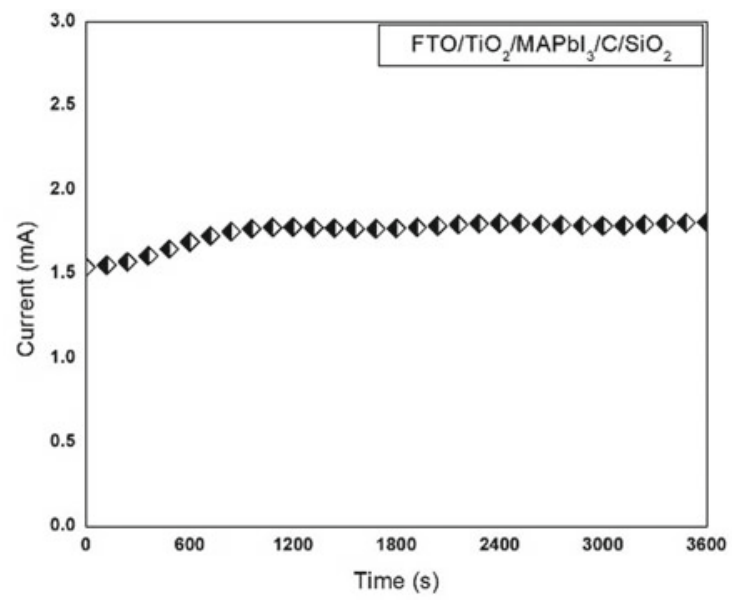


$0.1 \mathrm{M}$ aqueous $\mathrm{NaOH}$ solution. The soot coated photoelectrodes showed remarkable stability with currents remaining above $1.5 \mathrm{~mA} \mathrm{~cm}^{-2}$ for $\sim 1 \mathrm{~h}$ under constant illumination. This represents a first example of halide perovskite photoelectrode, protected with an inexpensive protection layer.

\subsection{Conclusion}

This work focusses on solving the long-standing moisture instability issue of halide perovskites through a simple, efficient and inexpensive protection route. The $\mathrm{FTO} / \mathrm{TiO}_{2} / \mathrm{MAPbI}_{3} / \mathrm{C} / \mathrm{SiO}_{2}$ photoelectrodes exhibited the potential to be employed as stable electrodes for water splitting in PEC hydrogen production, showing outstanding stability for $\sim 1 \mathrm{~h}$ in aqueous electrolyte. The perfect energy band alignment permitted carbon to be an efficient and directional hole extraction layer. While the excited electron moves from the conduction band (CB) at $-3.86 \mathrm{eV}$ of the $\mathrm{MAPbI}_{3}$ to the $\mathrm{CB}$ of $\mathrm{TiO}_{2}(-4.00 \mathrm{eV})$, the hole in the valence band (VB) at $-5.43 \mathrm{eV}$ is effectively extracted to the carbon layer (work function $5.00 \mathrm{eV}$ ). While the candle soot acted as an effective HTL due to its intimate contact with the perovskite layer, the $\mathrm{SiO}_{2}$ offered a more compact seal that protected the perovskite from the liquid electrolyte. The enormous stability coupled with the high photocurrent density makes these soot coated photoelectrodes an attractive device for application in a tandem photoelectrochemical cell for solar water splitting. Further research into the optimization of the electron transport layer and the use of more efficient perovskites can improve both stability and efficiency.

Acknowledgements This research has been supported by the Department of Chemistry, Dayalbagh Educational Institute, Agra, India and MNRE, Govt. of India project No. 103/241/2015-NT. We are thankful to the Department for providing the experimental and characterization facilities. We also thank Dr Karen Syres (University of Central Lancashire) for many valuable suggestions.

\section{References}

1. UN Framework Convention on Climate Change Secretariat, Paris Agreement FCCC/CP/2015/L.9/Rev.1 (2015)

2. S. Tapio, M.K. Colleen, G.P. Kyle, Possible climate transitions from breakup of stratocumulus decks under greenhouse warming. Nat. Geosci. 12, 163-167 (2019)

3. L. Sydney et al., World ocean heat content and thermosteric sea level change (0-2000 m), 1955-2010. Geophys. Res. Lett. 39, 10 (2012)

4. B. Tadeusz, T.N. Janusz, R. Mieczyslaw, S. Charles, Photo-electrochemical hydrogen generation from water using solar energy. Materials-related aspects. Int. J. Hydrog. Energy 27, 991-1022 (2001)

5. N.Z. Muradov, T.N. Veziroğlu, From hydrocarbon to hydrogen-carbon to hydrogen economy. Int. J. Hydrog. Energy 30, 225-237 (2005) 
6. B. Dowon, S. Brian, C.K.V. Peter, H. Ole, C. Ib, Strategies for stable water splitting: via protected photoelectrodes. Chem. Soc. Rev. 46, 1933-1954 (2017)

7. J.J. Nam et al., Compositional engineering of perovskite materials for high performance solar cells. Nature 517, 476-480 (2015)

8. H.N. Jun, H. Sang, H.H. Jin, N.M. Tarak, I.S. Sang, Chemical management for colorful, efficient, and stable inorganic-organic hybrid nanostructured solar cells. Nano Lett. 13, 1764-1769 (2013)

9. B. Sai et al., High-performance planar heterojunction perovskite solar cells: preserving long charge carrier diffusion lengths and interfacial engineering. Nano Res. 7, 1749-1758 (2014)

10. W. Christian, E. Giles, B.J. Michael, J.S. Henry, M.H. Laura, High charge carrier mobilities and lifetimes in organolead trihalide perovskites. Adv. Mater. 26, 1584-1589 (2014)

11. S. Dong et al., Low trap-state density and long carrier diffusion in organolead trihalide perovskite single crystals. Science 347, 519-522 (2015)

12. NREL's 'Best Research-Cell Efficiencies'. https://www.nrel.gov/pv/assets/pdfs/pv-efficienc ies-07-17-2018.pdf. Accessed 14 December 2018

13. P. Bertrand, P. Byung-Wook, L. Rebecka, O. Johan, A. Sareh, M.J.J. Erik, R. Hakan, Chemical and electronic structure characterization of lead halide perovskites and stability behavior under different exposures - a photoelectron spectroscopy investigation. Chem. Mater. 27, 1720-1731 (2015)

14. K. Min, G.M. Silvia, S. Roberto, P. Annamaria, Enhanced solar cells stability by hygroscopic polymer passivation of metal halide perovskite thin film. Energy Environ. Sci. 11, 2609-2619 (2018)

15. P. Isabella, E. Salvador, C. Petra, Tetrabutylammonium cations for moisture-resistant and semitransparent perovskite solar cells. J. Mater. Chem. A 5, 22325-22333 (2017)

16. Z. Masahito, S. Atsushi, A. Tsuyoshi, O. Takeo, Fabrication and characterization of $\mathrm{TiO}_{2} / \mathrm{CH}_{3} \mathrm{NH}_{3} \mathrm{PbI}_{3}$-based photovoltaic devices. Chem. Lett. 43(6), 916-918 (2014)

Open Access This chapter is licensed under the terms of the Creative Commons Attribution 4.0 International License (http://creativecommons.org/licenses/by/4.0/), which permits use, sharing, adaptation, distribution and reproduction in any medium or format, as long as you give appropriate credit to the original author(s) and the source, provide a link to the Creative Commons license and indicate if changes were made.

The images or other third party material in this chapter are included in the chapter's Creative Commons license, unless indicated otherwise in a credit line to the material. If material is not included in the chapter's Creative Commons license and your intended use is not permitted by statutory regulation or exceeds the permitted use, you will need to obtain permission directly from the copyright holder.

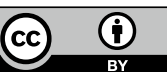

